\title{
Memory function in women with premenstrual complaints and the effect of serotonergic stimulation by acute administration of an alpha-lactalbumin protein
}

Citation for published version (APA):

Schmitt, J. A. J., Jorissen, B. L., Dye, L., Markus, C. R., Deutz, N. E., \& Riedel, W. J. (2005). Memory function in women with premenstrual complaints and the effect of serotonergic stimulation by acute administration of an alpha-lactalbumin protein. Journal of Psychopharmacology, 19(4), 375-384. https://doi.org/10.1177/0269881105053288

Document status and date:

Published: 01/01/2005

DOI:

10.1177/0269881105053288

Document Version:

Publisher's PDF, also known as Version of record

\section{Document license:}

Taverne

\section{Please check the document version of this publication:}

- A submitted manuscript is the version of the article upon submission and before peer-review. There can be important differences between the submitted version and the official published version of record. People interested in the research are advised to contact the author for the final version of the publication, or visit the DOI to the publisher's website.

- The final author version and the galley proof are versions of the publication after peer review.

- The final published version features the final layout of the paper including the volume, issue and page numbers.

Link to publication

\footnotetext{
General rights rights.

- You may freely distribute the URL identifying the publication in the public portal. please follow below link for the End User Agreement:

www.umlib.nl/taverne-license

Take down policy

If you believe that this document breaches copyright please contact us at:

repository@maastrichtuniversity.nl

providing details and we will investigate your claim.
}

Copyright and moral rights for the publications made accessible in the public portal are retained by the authors and/or other copyright owners and it is a condition of accessing publications that users recognise and abide by the legal requirements associated with these

- Users may download and print one copy of any publication from the public portal for the purpose of private study or research.

- You may not further distribute the material or use it for any profit-making activity or commercial gain

If the publication is distributed under the terms of Article 25fa of the Dutch Copyright Act, indicated by the "Taverne" license above, 


\section{Memory function in women with premenstrual complaints and the effect of serotonergic stimulation by acute administration of an alpha- lactalbumin protein}

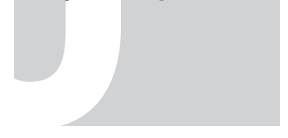

Journal of Psychopharmacology 19(4) (2005) 375-384 (c) 2005 British Association for Psychopharmacology ISSN 0269-8811 SAGE Publications Ltd, London, Thousand Oaks, CA and New Delhi 10.1177/0269881105053288

Jeroen A. J. Schmitt Experimental Psychopharmacology Unit, Brain \& Behaviour Institute, Universiteit Maastricht, Maastricht, The Netherlands. Nestlé Research Center, Lausanne, Switzerland.

Brenda L. Jorissen Experimental Psychopharmacology Unit, Brain \& Behaviour Institute, Universiteit Maastricht, Maastricht, The Netherlands. Louise Dye Institute of Psychological Sciences, University of Leeds, Leeds, UK.

C. Rob Markus Department of Experimental Psychology, Universiteit Maastricht, Maastricht, The Netherlands. Nicolaas E. P. Deutz Department of Surgery, Universiteit Maastricht, Maastricht, The Netherlands.

Wim J. Riedel Experimental Psychopharmacology Unit, Brain \& Behaviour Institute, Universiteit Maastricht, Maastricht, The Netherlands. Department of Psychiatry, University of Cambridge, Cambridge, UK. Department of Neurocognition, Faculty of Psychology, Universiteit Maastricht, Maastricht, The Netherlands.

\begin{abstract}
Serotonergic hypofunction may underlie at least part of the symptoms that are experienced by women with premenstrual complaints, including memory deficits. In the current study we investigated changes in memory functions in the premenstrual phase compared to the early postmenstrual phase in 16 women with premenstrual complaints. In addition, the effect of an acute serotonergic stimulation by administration of an alphalactalbumin protein on premenstrual memory performance was assessed using a double-blind placebo-controlled crossover design. It was found that both short-term and long-term memory for words (30-word learning task) and abstract figures (abstract visual learning task) were mildly impaired in the premenstrual phase. Administration of alpha-lactalbumin during the premenstrual phase could only partially attenuate the memory
\end{abstract}

\section{Introduction}

It is estimated that as many as $75 \%$ of women in the reproductive age experience physical and psychological distress in the late luteal phase of their menstrual cycle (Ramcharan et al., 1992). These premenstrual symptoms typically remit within days of menses and most commonly consist of mood swings, irritability, anxiety, breast tenderness, bloating and cognitive complaints such as poor concentration, confusion and forgetfulness. Persistent performance decrements that are seen in the premenstrual phase. Specifically, alphalactalbumin improved long-term memory for abstract figures, but not for words. There were no effects of menstrual phase or alpha-lactalbumin on planning functions (computerized Tower of London). The data suggest that serotonergic hypofunction may play a role in premenstrual memory decline, but serotonergic mechanisms cannot fully account for observed cognitive changes in the premenstrual phase.

\section{Keywords}

alpha-lactalbumin, tryptophan, serotonin, memory, premenstrual symptoms

reoccurrence of these symptoms and associated dysfunction in the social and work environment may lead to the diagnosis Premenstrual Syndrome (PMS) (Freeman, 2003; Rapkin, 2003) or, in particularly severe cases, Premenstrual Dysphoric Disorder (PMDD) (APA, 1994). Epidemiological studies using retrospective reports suggest that between 3 and $9 \%$ of women suffer from severe premenstrual symptoms or PMDD (Halbreich et al., 2003).

It has been proposed that women with PMS and PMDD have a different sensitivity to normal gonadal steroid fluctuations during 
each menstrual cycle than asymptomatic women (Schmidt et al., 1998) and this increased sensitivity may at least be partially related to central serotonergic mechanisms (Bethea et al., 2002). Both state and trait-related serotonergic abnormalities have been reported in women with premenstrual symptoms (see Kouri and Halbreich, 1997; Halbreich, 2003). These include reductions in platelet serotonin re-uptake (Taylor et al., 1984; Ashby et al., 1988) and lower whole blood serotonin levels (Taylor et al., 1984; Rapkin et al., 1987) specifically in the late luteal phase, as well as blunted prolactin responses to serotonergic challenges (Bancroft et al., 1991; FitzGerald et al., 1997) and reduced imipramine (Rojansky et al., 1991; Steege et al., 1992) or paroxetine (Melke et al., 2003) receptor binding that may be present throughout the menstrual cycle. The clinical relevance of these abnormalities has not yet been determined, but these findings together with the consistent efficacy of specific serotonergic re-uptake inhibitors (SSRIs) in treating premenstrual symptoms (Dimmock et al., 2000; Pearlstein, 2002) strongly suggest an etiological involvement of serotonin.

Although serotonergic dysfunction is usually primarily associated with depressed mood, irritability and affect lability, recent evidence suggests that serotonin is also implicated in cognitive functioning. A reduction of brain serotonergic activity, by means of acute tryptophan depletion, has been consistently associated with a specific impairment of long-term memory performance, independent of mood changes (Riedel et al., 1999, 2002; Schmitt et al., 2000; Rubinsztein et al., 2001; Sobczak et al., 2002; Harrison et al., 2004). Following this premise, women with premenstrual symptoms may be prone to memory deficits, either throughout their menstrual cycle (trait) or particularly during the premenstrual phase (state). In these women anecdotal and subjective complaints of premenstrual forgetfulness are quite common. Unfortunately, objective memory assessments in women with PMS or PMDD across the menstrual cycle are rather scarce. A phase-independent impairment of short-term and long-term memory for verbal, but not abstract, material was reported in women with PMS compared to controls (Keenan et al., 1995). Others have failed to detect overall or phase-dependent differences in memory function between women with PMS/PMDD and controls (Morgan et al., 1996; Resnick, 1998). However, women with PMS were found to be significantly more sensitive to the detrimental effects of alprazolam on memory in the premenstrual phase, perhaps suggesting that memory function becomes vulnerable to disruption in the late luteal phase. Interestingly, increasing the availability of serotonin's precursor L-tryptophan (TRP) in premenstrual women with PMS has been shown to improve mood (Steinberg et al., 1999) and verbal recognition memory (Sayegh et al., 1995). Although improved memory performance may arise indirectly from elevated mood, a direct serotonergic mechanism independent of mood cannot be ruled out.

The aim of the current study was (1) to investigate changes in memory function across the menstrual cycle, specifically during the late luteal (premenstrual) phase compared to the follicular (postmenstrual) phase, in women with premenstrual complaints and (2) to investigate the effects of stimulation of serotonergic neurotransmission by acute administration of a L-tryptophan-rich protein, alpha-lactalbumin, on memory performance in these women. L-Tryptophan (TRP) is the precursor for 5-HT synthesis and dietary manipulation of brain TRP availability is a well-established method to modify central 5-HT function in humans (Young, 1996; Reilly et al., 1997). Administration of alpha-lactalbumin has previously been shown to significantly elevate a peripheral marker of central TRP availability, i.e. plasma concentration of TRP relative to that of five other amino acids (large neutral amino acids: leucine, isoleucine, valine, tyrosine and phenylalanine) that compete for active transport across the blood-brain barrier, denoted as TRP/ $\Sigma$ LNAA ratio (Markus et al., 2000a, 2002).

To establish the specificity of the memory effects, executive functioning was also assessed. Based on the considerations above, it is expected that long-term memory function will be reduced during the premenstrual phase and that this long-term memory deficit can be alleviated by administration of the alpha-lactalbumin protein.

\section{Methods}

\section{Participants}

Volunteers were recruited through advertisements and posters on the campus of the University of Leeds. Sixteen women, aged $18-45$ years $($ mean $=29, \mathrm{SE}=2)$ suffering from premenstrual symptoms were included in the study. Inclusion criteria were selfreported moderate to severe premenstrual changes in mood, affect, well-being and cognitive function, assessed by the Calendar Of Premenstrual Experience (COPE) (Mortola et al., 1990); a reported history of these premenstrual complaints for more than 2 years and a regular menstrual cycle. Symptoms were assessed by the Freemans Daily Symptom Diary (DSR) (Freeman et al., 1996) during one complete menstrual cycle. Total premenstrual symptoms increased by $48 \%$ in the premenstrual versus the postmenstrual period. The premenstrual mood, behavioural, pain and physical symptoms subscales increased by $44 \%, 30 \%, 69 \%$ and $76 \%$ respectively.

Exclusion criteria were oral contraceptive use, hormone replacement therapy, history of depressive disorder, pregnancy, breast feeding, any medical disorder that could produce cognitive deterioration, excessive alcohol use and current psychoactive medication. The study was approved by the ethics committee of the University of Maastricht and the Chair of the United Leeds Teaching Hospital Trust's Ethics Committee. All subjects gave written informed consent prior to participation. Fifteen women completed the study. One woman withdrew as a result of pneumonia.

\section{Design}

The treatment part of this study was conducted according to a double-blind, placebo-controlled, crossover design. The participants received a standardized meal with a chocolate drink containing either the whey protein concentrate rich in alpha-lactalbumin or casein (control condition) on two premenstrual days (between days 22 and 28 of the menstrual cycle). Treatment order was coun- 
terbalanced. Cognitive performance was assessed before (baseline) and after the nutritional manipulation.

Each subject also completed a test battery in the postmenstrual phase of their menstrual cycle (between days 4 and 8), and this postmenstrual performance was compared to premenstrual performance, defined as the average of the baseline assessments of the two premenstrual days. The order of the test days was counterbalanced, with 16 premenstrual assessments done before and 14 after the postmenstrual assessments.

\section{Treatments}

On both premenstrual test days, the participants received a standardized low-protein diet, which consisted of a breakfast, snack and lunch. Breakfast and lunch were identical in composition: $35 \mathrm{~g}$ bread, $15 \mathrm{~g}$ butter, $35 \mathrm{~g}$ strawberry jam, $200 \mathrm{ml}$ red grape fruit juice and $15 \mathrm{~g}$ malt bread. The snack was a $42 \mathrm{~g}$ chocolate bar and $100 \mathrm{ml}$ of red grape fruit juice. In addition to this diet, two chocolate drinks $(200 \mathrm{ml})$ were served, each containing either $20 \mathrm{~g}$ of a whey protein rich in alpha-lactalbumin (Vivinal Alpha, Borculo Domo Ingredients, Borculo; The Netherlands) or $15.5 \mathrm{~g}$ casein (control condition) (see Table 1). One drink was served with the breakfast, the other with lunch (Markus et al., 2000a, 2002). On both occasions, the meals including the chocolate/protein drinks (alpha-lactalbumin or sodium caseinate) were iso-caloric, with a total energy content of $6133 \mathrm{~kJ}$. Carbohydrates provided $63.5 \%$ of energy intake, protein $11.7 \%$ and fat $24.8 \%$.

Table 1 Compositions and large neutral amino acid profiles of the chocolate drinks containing alpha-lactalbumin or casein protein

\begin{tabular}{lcc}
\hline & $\begin{array}{l}\text { Alpha-lactalbumin } \\
\text { drink }\end{array}$ & Casein drink \\
\hline Composition & & \\
$\quad$ Whey protein rich in alpha- & & \\
$\quad$ lactalbumin (g) & 20 & - \\
Casein (g) & - & 15.5 \\
Cocoa powder (g) & 3.5 & 3.5 \\
Granulated sugar (g) & 10 & 10 \\
Water (ml) & 200 & 200 \\
Large neutral amino acid & & \\
$\quad$ profile $(\mathrm{g} / \mathrm{kg})$ & & \\
Isoleucine & 27.61 & 31.80 \\
Leucine & 47.56 & 59.31 \\
Phenylalanine & 20.80 & 32.24 \\
Tyrosine & 16.82 & 33.13 \\
Valine & 29.52 & 44.09 \\
Tryptophan & 12.32 & 9.51 \\
Tryptophan/LNAA (\%) & 8.7 & 4.7 \\
\hline
\end{tabular}

${ }^{1} \mathrm{Trp} /$ LNAA: the ratio of total plasma concentrations of tryptophan to the sum of the other large neutral amino acids.

\section{Procedure}

During a separate training session each participant practised the cognitive tests in order to minimize procedural learning effects. The participants were instructed not to drink alcohol on the day prior to the test days, not to eat or drink anything except water after $10 \mathrm{PM}$ that evening, and to arrive at the laboratory wellrested. Ovulation detection kits were used to determine an appropriate date for the premenstrual assessments (approximately 10 days post-ovulation with adjustments for individual cycle length).

Fig. 1 shows a schematic representation of the premenstrual test days. Each test day started at 8 or $9 \mathrm{AM}(t-1)$ with the baseline cognitive assessments and blood sampling. On both premenstrual test days this was followed by one of the dietary interventions, consisting of a breakfast with a casein or alpha-lactalbumin drink $(t 0)$, a snack $(t 1.25)$ and a lunch with a casein or alpha-lactalbumin drink ( $t 2)$. Between meals, participants were allowed to watch videos, read books or work in their office on campus. At $t 3.5$ a second blood sample was taken, followed by cognitive assessments starting at $t 4$ and a final blood sample at $t 5$. The postmenstrual test day consisted of the baseline measurements only.

\section{Cognitive assessments}

The cognitive test battery took approximately 45 min to complete. Parallel versions of each task were used on each occasion. Version order was balanced using a Latin Square.

\section{Primary cognitive outcome measures}

Short-term and long-term declarative memory was assessed using two memory tests that have been shown to be sensitive to changes in central serotonergic activity through dietary TRP manipulations (acute tryptophan depletion) (Rubinsztein et al., 2001; Riedel et al., 2002).

30 Word Learning Test The 30 Word Learning Test is adapted from the Rey Auditory Verbal Learning Test (Rey, 1964). A word list, consisting of 30 monosyllabic words matched for frequency,

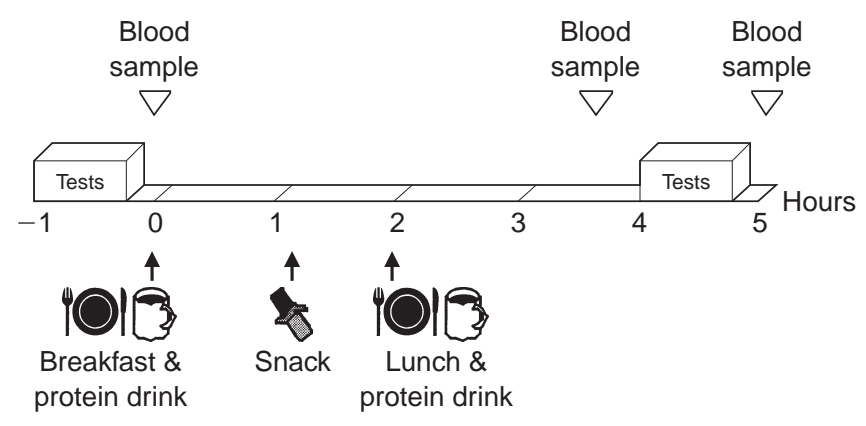

Figure 1 Schematic representation of a premenstrual test day 
imagery and concreteness, was presented in the same sequence in three trials on a computer screen at a rate of one word per $2 \mathrm{~s}$. Each presentation ended with a free verbal recall of the words (immediate recall). Thirty minutes after the third presentation, the participant was requested to recall as many words as possible from the list she had seen earlier (delayed recall). This was followed by a recognition trial, in which 15 formerly learned words and 15 new words were presented. Subjects had to respond to each word as fast as possible by pressing a 'YES or NO' button to indicate recognition. According to the theory of signal detection (Pollack and Norman, 1964), the proportion of correctly recognized words (cr) and the proportion of falsely recognized (fr) constitute the nonparametric sensitivity measure: $\mathrm{A}^{\prime}=1-1 / 4(\mathrm{fr} / \mathrm{cr}+(1-\mathrm{cr}) /(1-\mathrm{fr}))$. $\mathrm{A}^{\prime}$ is in fact the proportion of correctly recognized words, corrected for the participant's response tendency. Because the distribution of $\mathrm{A}^{\prime}$ is skewed due to a ceiling effect, $\mathrm{A}^{\prime}$ was arcsin transformed before statistical analysis.

The outcome variables were the total number of correct words recalled during the three immediate recall trials as a measure of short-term memory, the number of correct words produced on delayed free recall as a measure of retrieval from long-term memory, $\mathrm{A}^{\prime}$ as a measure of storage in long-term memory, and the median reaction times of correctly recognized words as a measure of speed of long-term memory.

Abstract Visual Pattern Learning Task A series of 16 patterns, consisting of black and white blocks in a $6 \times 4$ matrix, was presented three times on a computer screen at a rate of one per $3.5 \mathrm{~s}$. Participants were instructed to memorize the patterns as accurately as possible, for recognition immediately after the three trials and again after a 30-min delay. During the forced recognition trials, 16 pairs of patterns, consisting of a target and a distracter, were shown. Target and distracter patterns were equally distributed over the left and right side of the screen. Subjects responded by pushing a 'left' or 'right' button to indicate the position of the pattern they recognized. The median reaction times of the correct responses and sensitivity measures ( $\mathrm{A}^{\prime}$, see Word Learning Test) were dependent variables.

\section{Secondary cognitive outcome measures}

Computerized Tower of London To establish the specificity of menstrual cycle and/or treatment effects on memory, a modified version of the One-touch Tower of London task (Owen et al., 1995) was incorporated in the test battery to measure executive functioning (planning capacity).

During the training session participants were first familiarized with the original Tower of London (Shallice, 1982). Subsequently, the computerized Tower of London was introduced. On a computer screen, two arrays of three coloured balls (red, yellow and blue) on three sticks were presented. The participant was requested to indicate the minimum number of steps necessary to rearrange three coloured balls on the top configuration to match the configuration on the lower half of the screen by pressing the appropriate response button (2-6 steps). The tests consisted of 40 trials, with an equal number of 2, 3, 4 and 5-steps problems, which were presented in a fixed pseudo-random order. To avoid particip- ants responding automatically with a 5-steps response when the problem appeared to be too complex, four 6-steps trials were added, which were not used in the data-analysis.

Reaction times of the individual responses were transformed according to the equation: $y=\operatorname{sqrt}(10 \log (\mathrm{RT}))$, so that transformed RTs ( $y$ ) are a linear function of the number of steps. Linear regression analyses were then carried out on transformed RTs to yield individual slopes and intercepts of the RT on steps functions. Slope is considered the primary outcome variable measuring problemsolving ability. Intercept is a variable measuring response speed unrelated to problem-solving ability. As no consistent association has been established between number of errors and the number of steps, the total number of errors is the third outcome variable.

\section{Blood samples}

Blood samples were collected in $4 \mathrm{ml}$ lithium heparin tubes by means of venepuncture and immediately placed on ice. The blood samples were centrifuged for $5 \mathrm{~min}$ at $4000 \mathrm{rpm}$ at $4{ }^{\circ} \mathrm{C}$ within $30 \mathrm{~min}$ after collection. Subsequently, $100 \mu \mathrm{l}$ plasma was deproteinized by vortexing with $6 \mathrm{mg}$ sulfosalicyclic acid. The deproteinized plasma was frozen in dry ice and stored at $-70^{\circ} \mathrm{C}$ until quantitative amino acid analysis using high-performance liquid chromatography was carried out (van Eijk et al., 1993). Total amino acid concentrations were used for calculation of the TRP/LNAA ratios.

\section{Statistical analysis}

\section{Premenstrual versus postmenstrual performance}

Average baseline $(t-1)$ level of performance on both premenstrual test days was compared to postmenstrual performance by means of a repeated measures analyses of variance (ANOVA) using 'Phase' (2 levels: premenstrual, postmenstrual) as a withinsubjects factor, and 'Phase order' (3 levels: pre-pre-post, pre-postpre, post-pre-pre) as between-subjects factor.

\section{Effect of alpha-lactalbumin}

Difference scores were calculated for the outcome variables by subtracting baseline $(t-1)$ scores from scores at the $t 4$ assessment. The resulting variables were analysed by a repeated measures ANOVA using 'Treatment' (two levels: alpha-lactalbumin, casein) as a within-subjects factor, and 'Treatment order' as a between-subjects factor. For analysis of the blood parameters, 'Time' (two levels: $t 3.5, t 5$ ) was added as a within-subjects factor.

\section{Results}

One subject did not complete the Tower of London on one occasion. Due to difficulties in blood sampling, plasma amino acid levels of three subjects could not be determined. The results of the cognitive assessments are summarized in Table 2. 
Table 2 Means (SE) of the cognitive outcome measures at baseline $(t-1)$ and $4 \mathrm{~h}$ after start of the casein or alpha-lactalbumin treatment $(t 4)$ during the premenstrual assessments, and at the postmenstrual assessment. Asterisks denote a significant $\left({ }^{*} p<0.05,{ }^{* *} p<0.01\right)$ difference between the premenstrual (average baseline scores) and postmenstrual scores

\begin{tabular}{|c|c|c|c|c|c|}
\hline \multirow[b]{3}{*}{ Cognitive measure } & \multicolumn{4}{|l|}{ Premenstrual } & \multirow[b]{3}{*}{ Postmenstrual } \\
\hline & \multicolumn{2}{|l|}{ Baseline $(t-1)$} & \multicolumn{2}{|l|}{$t 4$} & \\
\hline & Alpha-lactalbumin & Casein & Alpha-lactalbumin & Casein & \\
\hline \multicolumn{6}{|l|}{ Word-learning test } \\
\hline Immediate recall (\# words) & $50.6(3.6)$ & $53.2(2.6)$ & $51.5(2.5)$ & $48.7(3.4)$ & $57.2(2.7)^{*}$ \\
\hline Delayed recall (\# words) & $18.0(1.3)$ & $18.7(1.3)$ & $15.2(1.5)$ & $14.9(1.6)$ & $18.4(1.5)$ \\
\hline Delayed recognition $\left(A^{\prime}\right)$ & $96.3(1.0)$ & $97.3(0.8)$ & $95.2(0.8)$ & $96.2(0.8)$ & $96.9(0.8)$ \\
\hline Delayed recognition speed (msec) & $682(24)$ & $692(16)$ & $719(25)$ & $686(21)$ & $633(18)^{\star *}$ \\
\hline \multicolumn{6}{|l|}{ Abstract Visual Pattern Learning } \\
\hline Immediate recognition $\left(\mathrm{A}^{\prime}\right)$ & $93.7(1.9)$ & $93.0(2.1)$ & $90.4(2.2)$ & $94.7(0.9)$ & $94.8(1.3)$ \\
\hline Immediate recognition speed (msec) & $1630(102)$ & $1514(98)$ & $1545(74)$ & $1528(79)$ & $1412(76)^{*}$ \\
\hline Delayed recognition $\left(\mathrm{A}^{\prime}\right)$ & $88.9(3.0)$ & $91.0(3.4)$ & $91.9(1.7)$ & $90.9(2.6)$ & $92.2(2.0)$ \\
\hline Delayed recognition speed (msec) & $1722(125)$ & $1555(86)$ & $1519(69)$ & $1706(111)$ & $1447(98)^{*}$ \\
\hline \multicolumn{6}{|l|}{ Tower of London } \\
\hline Slope & $0.14(0.01)$ & $0.15(0.01)$ & $0.15(0.01)$ & $0.15(0.01)$ & $0.15(0.01)$ \\
\hline Intercept & $3.50(0.03)$ & $3.46(0.04)$ & $3.47(0.02)$ & $3.44(0.04)$ & $3.46(0.03)$ \\
\hline Errors (\# responses) & $7.5(1.3)$ & $7.0(1.0)$ & $7.4(1.2)$ & $7.1(1.0)$ & $6.3(0.9)$ \\
\hline
\end{tabular}

\section{Premenstrual versus postmenstrual assessments}

Plasma amino acid levels Baseline plasma tryptophan/ LNAA ratios did not differ between the premenstrual phase and the postmenstrual phase (Fig. 2).

Cognitive performance As for the cognitive assessments, the total number of words produced in the immediate recall trials of the word learning test was significantly lower during the premenstrual assessments compared to the postmenstrual assessment $[F 1,12=5.29 ; p<0.05]$. Delayed recall and delayed recognition accuracy showed no differences across the menstrual cycle. However, reaction times for the delayed recognition responses were increased in the premenstrual phase compared to the postmenstrual phase $[F 1,12=12.11 ; p<0.01]$.

Accuracy of the immediate and delayed recognition on the abstract visual recognition task did not differ across the menstrual cycle. In the premenstrual phase, reaction time was increased at both the immediate $[F 1,12=5.10 ; p<0.05]$ and the delayed recognition assessment $[F 1,12=5.50 ; p<0.05]$.

The average linearity of the calculated RT $\times$ task difficulty functions of the Tower of London varied between 0.94 to 0.98 at the different assessment points. The outcome measures of the Tower of London, i.e. slope, intercept and number of errors, showed no differences between the premenstrual and postmenstrual test sessions.

There were no main effects of 'phase order' or 'phase order' by 'phase' interactions.

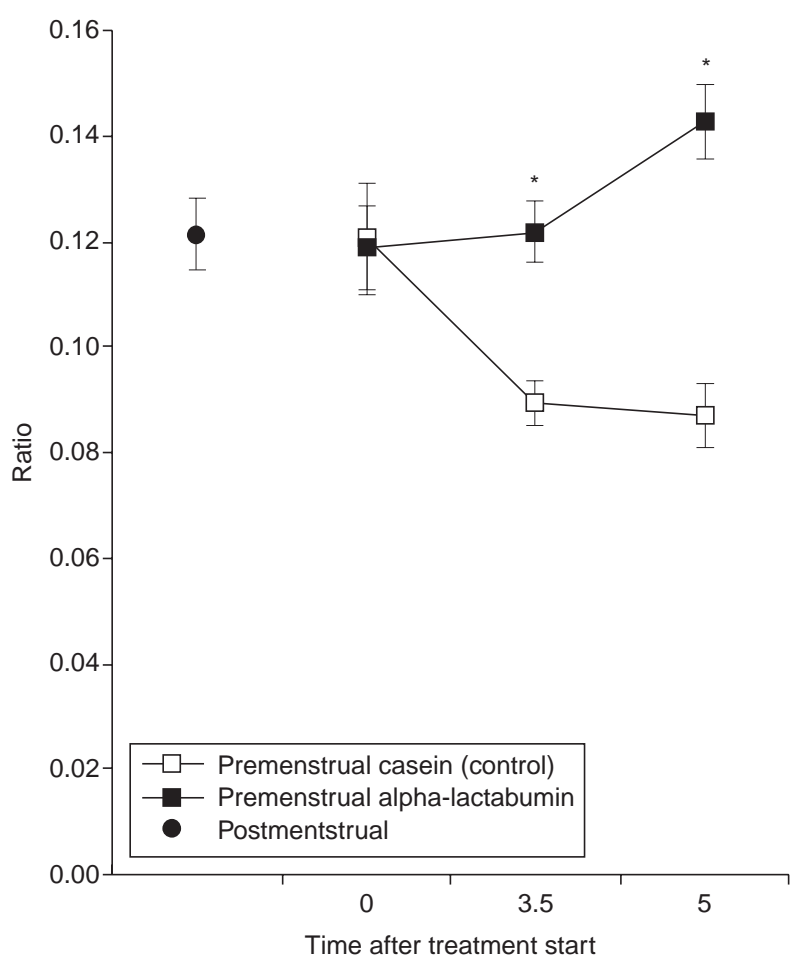

Figure 2 Mean (SE) tryptophan/SLNAA ratios at the postmenstrual assessment, and the premenstrual assessments at baseline (t0) and at 3.5 and 5 hours after start of the treatment. ${ }^{*} p<0.05$ versus the casein condition 


\section{The effect of alpha-lactalbumin administration}

Plasma amino acid levels The plasma tryptophan/LNAA ratios showed a main effect of treatment $[F 1,11=13.36 ; p<0.01]$ and significant interaction between treatment and time $[F 1,11=5.11$; $p<0.05]$. Following alpha-lactalbumin administration, the tryptophan/LNAA ratios increased by $6 \%$ at $t 3.5$ and $25 \%$ at $t 5$ compared to baseline. A decrease of $22 \%$ and $25 \%$ was seen at $t 3.5$ and $t 5$ respectively following casein administration. In the alphalactalbumin condition the plasma tryptophan/LNAA ratios were $38 \%(t 3.5)$ and $70 \%(t 5)$ higher than in the casein condition (see Fig. 2).

Cognitive performance Administration of the alpha-lactalbumin protein resulted in significantly faster responses in the delayed recognition trials of the abstract visual recognition task $[F 1,13=5.71 ; p<0.05]$ (see Fig. 3) compared to placebo. No effects of alpha-lactalbumin on the other outcome variables of the abstract visual recognition task, the word learning task and the Tower of London were observed.

Main effects of treatment order were observed for the accuracy on the immediate recognition trial $[F 1,13=6.83 ; p<0.05]$ and the speed of the delayed recognition trial of the abstract visual recognition task $[F 1,13=5.24 ; p<0.05]$, and the slope of the Tower of London $[F 1,12=6.85 ; p<0.05]$. A significant treatment order by treatment interaction was found in the analysis of the speed of the immediate recognition trial of the abstract visual recognition task $[F 1,13=7.68 ; p<0.05]$. It appeared that alpha-lactalbumin improved performance when given on the first occasion, but

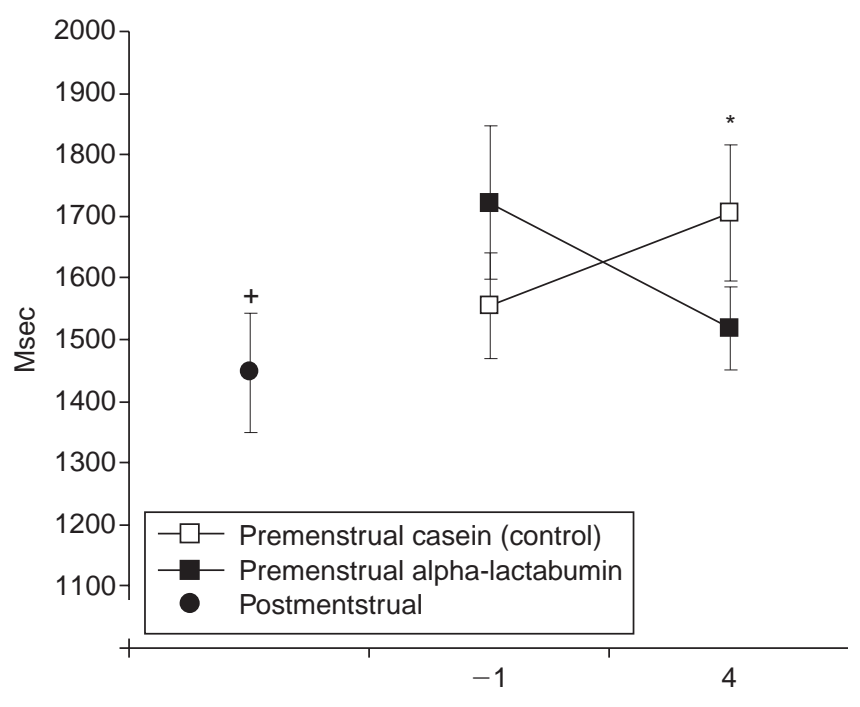

Time after treatment start

Figure 3 Mean (SE) reaction times of the delayed recognition trails of the abstract visual learning task at the postmenstrual assessment, and premenstrual assessments at baseline $(t-1)$ and 4 hours after start of the treatment. $+p<0.05$ versus premenstrual baseline average, ${ }^{*} p<0.05$ versus the control treatment impaired performance when given on the second day. However, separate paired $t$-tests revealed no significant differences between placebo and alpha-lactalbumin when alpha-lactalbumin was given on the first test day $(t(7)=2.11$, n.s.) or on the second test day $(t(8)=-2.00$, n.s. $)$. No other interactions between treatment order and treatment were observed.

Correlation between amino acid levels and cognitive measures A significant correlation $(R=-0.64, p=0.024, n=12)$ was found for the alpha-lactalbumine-placebo difference in delayed recognition reaction time and TRP/LNAA ratio at $t 5$, but the significance level did not survive Bonferroni correction for multiple testing. There were no other significant correlations between TRP/LNAA ratio and cognitive outcome variables.

\section{Discussion}

We examined changes in memory and executive functions across the menstrual cycle in women with premenstrual complaints and the cognitive effects of acute premenstrual administration of alpha-lactalbumin to stimulate central serotonergic activity. The results show that, in accordance with our hypothesis, memory functions in the premenstrual phase are significantly, albeit mildly, impaired compared to the postmenstrual phase. Reduced performance was apparent in several short-term memory measures, i.e. immediate recall trials of the word learning test and immediate recognition speed in the abstract visual pattern learning task, as well as in several long-term memory measures, i.e. delayed recognition speed in the word learning test and the abstract visual pattern learning task. Executive functioning and psychomotor speed, as measured by the Tower of London, was similar in the premenstrual and postmenstrual phase. Administration of alphalactalbumin in the premenstrual phase decreased reaction times for correct responses on the delayed recognition trail.

In contrast to the prevalent cultural stereotype and subjectively reported cognitive complaints, the majority of neuropsychological studies have failed to show a robust decline in cognitive abilities in the late luteal phase (Ussher and Wilding, 1991; Nakatani et al., 1993; Cockerill et al., 1994; Epting and Overman, 1998; Mumenthaler et al., 2001), even in women diagnosed with PMS or PMDD (Morgan et al., 1996; Resnick, 1998; Man et al., 1999; Morgan and Rapkin, 2002). Our data show that several indices of memory functioning are subject to change during the menstrual cycle, indicating a decline in both short-term and long-term memory efficacy in the premenstrual phase. However, in line with previous observations, these cycle effects are modest and are reflected mostly in a reduction of the speed of memory processing, rather than decrements in accuracy. Slowing of responses on the memory tests cannot be attributed to a general reduction of psychomotor speed, as the intercept measure of the Tower of London, a specific measure of psychomotor function, was unchanged. Reduced accuracy was apparent only with regard to short-term memory for words. As pointed out by Morgan and Rapkin (2002), measures of reaction time are considered to be more sensitive and thus useful for assessing subtle cognitive changes during the men- 
strual cycle. A tentative interpretation of the observed reduction of recognition speed would be that this reflects greater difficulty and increasing effort to maintain optimal memory performance in terms of accuracy. The sensation of the necessity for more effortful processing may underlie subjective complaints of forgetfulness and loss of concentration (Kahneman, 1973; Ussher and Wilding, 1991; Oken et al., 1995). It is also worth considering that the requirement of additional effort may result in more pronounced performance deficits over extended periods of cognitive demand, for example in an occupational setting.

Administration of alpha-lactalbumin resulted in a $25 \%$ increase in the TRP/LNAA ratio compared to baseline, which seems rather modest at first sight. However, it is noteworthy that a $25 \%$ decline in TRP/LNAA ration was observed in the control condition and that this decline is comparable to what is seen after a balanced meal (Rosenthal et al., 1989). This not only confirms the validity of the control treatment, in that it reflects the situation after a normal meal, but also shows that, compared to a naturalistic, balanced meal, the alpha-lactalbumin meal was able to induce a $70 \%$ increase in the TRP/LNAA ratio. A slightly less robust increase (43-48\%) in the ratio following alpha-lactalbumin administration has been shown to improve mood (Markus et al., 2000b) and to produce cognitive improvement in stress-vulnerable subjects (Markus et al., 2002). Although not measured in the current study, previous data show that administration of alpha-lactalbumin, at a dose identical to that used in the current study, produces a significant increase in peripheral markers of central serotonergic activity, i.e. prolactin and cortisol responses (Markus et al., 2000a, b). The increase in TRP/LNAA ratio in the current study is also comparable to the level achieved following carbohydrate loading $(+29 \%$ compared to baseline), which has been associated with premenstrual improvements in mood and memory function in women with PMS (Sayegh et al., 1995). A high carbohydrate load can increase TRP/LNAA ratios through insulin-mediated stimulation of protein synthesis, leading to the uptake of circulating LNAA's levels into peripheral tissues (Fernstrom and Wurtman, 1971). However, as little as $5 \%$ of protein in a meal is sufficient to block this effect (Teff et al., 1989). Given the protein content of the meal in the current study, it is not likely that carbohydrate intake has substantially contributed to the changes in TRP/LNAA ratios.

Alpha-lactalbumin administration was found to improve premenstrual memory function in terms of increased response speed in the delayed recognition trial of the abstract visual pattern learning task. Thus, alpha-lactalbumin administration attenuated a premenstrual performance decrement on this measure. Alleviation of premenstrual long-term memory impairment by serotonergic stimulation appears to be consistent with the notion of serotonergic hypofunction underlying premenstrual long-term memory decline. This finding fits nicely with various experiments showing specific long-term memory deficits following serotonergic inhibition (Riedel et al., 1999, 2002; Schmitt et al., 2000; Rubinsztein et al., 2001; Sobczak et al., 2002; Harrison et al., 2004), long-term memory improvement by serotonergic stimulation (Harmer et al., 2002) and corroborating evidence such as long-term memory impairment due to serotonergic degeneration following prolonged use of MDMA (Curran and Verheyden, 2003). However, the impairing effects of low 5-HT on memory have been shown to be independent of the nature of the presented visual stimuli, as it has been demonstrated for words (see Riedel et al., 2002), pictures (Sobczak et al., 2002) and abstract figures (Rubinsztein et al., 2001). It is therefore rather unexpected that alpha-lactalbumin did not alleviate the premenstrual impairment of long-term memory for words as well. Thus, although the overall pattern of results for the pre- versus postmenstrual comparison and the effect of alphalactalbumin supports the notion that low serotonin may be involved in some premenstrual performance deficits, it seems that serotonergic mechanisms cannot fully account for the observed premenstrual decrements. More specifically, although premenstrual deficits in long-term memory function are consistent with a low 5-HT hypothesis, short-term memory decrements are not (Riedel et al., 2002). Further, the observation that 5-HT stimulation, by means of alpha-lactalbumin supplementation, can attenuate premenstrual long-term memory for patterns, but not for words, also suggests that other, non-serotonergic, factors may modulate cognition during the premenstrual and/or menstrual phase. Particularly relevant in the current context is the positive relationship between serum levels of oestrogens and verbal memory in women (Phillips and Sherwin, 1992a, b; Kimura, 2002). One could speculate that during the premenstrual phase, low oestrogens levels and reduced 5-HT activity have additive detrimental effects on verbal memory, thereby decreasing the sensitivity of this function to serotonergic stimulation by alpha-lactalbumin. Although it must be noted that the literature on oestrogens' effects on verbal memory is rather inconsistent in terms of observed effects and correlations for various neuropsychological tasks in various populations (see e.g. Owens et al., 2002), the putative interaction between serotonergic and ovarian hormonal mechanisms with regard to cognitive performance across the menstrual cycle would be an interesting area for future research. Finally, although the deficits appear to be limited to memory functions, the possibility that non-specific mechanisms, for example increased premenstrual physical discomfort, may have contributed to the premenstrual performance deficits cannot be fully excluded.

Several possible limitations and methodological issues of the study should be addressed. First, because the reproducibility of the complaints was not prospectively assessed during two cycles, no diagnosis of PMS could be made based on the ACOG (American College of Obstetricians and Gynecologists) criteria (ACOG, 2000), nor could we formally diagnose PMDD (APA, 1994). Nevertheless, the cyclic reoccurrence of symptoms was confirmed retrospectively and our prospective assessment with the Daily Symptom Diary during one cycle showed that the severity of the symptoms (a 30-76\% premenstrual increase in symptoms, see participants section) meets the widely cited $30 \%$ criterion for marked change between premenstrual and postmenstrual symptoms necessary to confirm PMS, established by the National Institute for Mental Heath (Gold, 1994; Hamilton et al., 1984). Second, ovulation detection kits were used to calculate the appropriate assessment dates, which were then retrospectively confirmed by inspection of the premenstrual symptoms diaries and prospectively by the date of onset of the subsequent menstrual period. Although analyses of plasma oestrogen and progesterone 
levels would have been a more exact method of determining the correct menstrual cycle phase for assessments, the determination of two key events, ovulation and menses, permits an accurate calculation of individual pre- and postmenstrual phases (Epting and Overman, 1998). From the documented onset of menses, it was retrospectively verified that all premenstrual assessments were done in the last 7 days before menses. Third, since alpha-lactalbumin was only administered in the premenstrual phase, a comparison of the behavioural effects of alpha-lactalbumin across various menstrual cycle phases cannot be made. Hence, we cannot establish whether the positive cognitive effect of alpha-lactalbumin is specific to the premenstrual phase or extends to other phases as well. The latter would be plausible if low 5-HT is a trait rather than a state marker of PMS. As both trait-related 5-HT abnormalities (see Kouri and Halbreich, 1997; Halbreich, 2003) and phaseindependent memory deficits have been reported in PMS/PMDD (Keenan et al., 1995), comparing the effects of alpha-lactalbumin at various phases of the menstrual cycle would certainly be of interest.

In conclusion, our results indicate that women with premenstrual complaints demonstrate a mild deterioration of memory functioning during the premenstrual phase (days 22-28) compared to the postmenstrual phase (days 4-8). Premenstrual deficits, mostly manifest as decreased speed of memory functioning, were quite consistently found on both memory tasks. The cognitive effect of acute premenstrual administration of alpha-lactalbumin, in order to stimulate central 5-HT, was modest and limited to an improvement of long-term memory for abstract figures. The observed performance changes in the premenstrual phase and the effect of alpha-lactalbumin suggests that serotonergic hypofunction may play a role in premenstrual cognitive decline. However, it is clear that additional research is required to confirm this notion. Furthermore, serotonergic mechanisms cannot fully account for observed cognitive changes and it is likely that the pattern of cognitive, as well as other behavioural, changes in the premenstrual period is the result of a complex interplay between various neurobiological and hormonal mechanisms. Disentanglement of these interactions would be the challenge for future research.

\section{Acknowledgements}

This research was sponsored by the Netherlands Organization for Scientific Research (NWO) by means of a travel grant (R 98-152) to Brenda Jorissen. Borculo Domo Ingredients, Zwolle (the Netherlands) kindly supplied the alpha-lactalbumin protein. The authors wish to express their gratitude to Kirsty Brown, Claire Hill, Karen Irving and Lily Read for their advice, logistic support and/or medical assistance. The authors would also like to thank Profs T. W. Robbins and B. J. Sahakian, University of Cambridge (UK), for their collaborative efforts enabling the use of the onetouch Tower of London.

\section{References}

ACOG (American College of Obstetricians and Gynecologists) (2000) Premenstrual syndrome. ACOG Practice Bulletin 15

APA (1994) Diagnostic and Statistical Manual of Mental Disorders, 4th edn. American Psychiatric Association, Washington, DC

Ashby C R, Jr, Carr L A, Cook C L, Steptoe M M, Franks D D (1988) Alteration of platelet serotonergic mechanisms and monoamine oxidase activity in premenstrual syndrome. Biol Psychiatry 24: 225-233

Bancroft J, Cook A, Davidson D, Bennie J, Goodwin G (1991) Blunting of neuroendocrine responses to infusion of L-tryptophan in women with perimenstrual mood change. Psychol Med 21: 305-312

Bethea C L, Lu N Z, Gundlah C, Streicher J M (2002) Diverse actions of ovarian steroids in the serotonin neural system. Front Neuroendocrinol 23: $41-100$

Cockerill I M, Wormington J A, Nevill A M (1994) Menstrual-cycle effects on mood and perceptual-motor performance. J Psychosom Res 38: 763-771

Curran H V, Verheyden S L (2003) Altered response to tryptophan supplementation after long-term abstention from MDMA (ecstasy) is highly correlated with human memory function. Psychopharmacology 169: 91-103

Dimmock P W, Wyatt K M, Jones P W, O’Brien P M (2000) Efficacy of selective serotonin-reuptake inhibitors in premenstrual syndrome: a systematic review. Lancet 356: 1131-1136

Epting L K, Overman W H (1998) Sex-sensitive tasks in men and women: a search for performance fluctuations across the menstrual cycle. Behav Neurosci 112: 1304-1317

Fernstrom J D, Wurtman R J (1971) Brain serotonin content: increase following ingestion of carbohydrate diet. Science 174: 1023-1025

FitzGerald M, Malone K M, Li S, Harrison W M, McBride P A, Endicott J, Cooper T, Mann J J (1997) Blunted serotonin response to fenfluramine challenge in premenstrual dysphoric disorder. Am J Psychiatry 154: $556-558$

Freeman E W (2003) Premenstrual syndrome and premenstrual dysphoric disorder: definitions and diagnosis. Psychoneuroendocrinology 28 (Suppl. 3): 25-37

Freeman E W, DeRubeis R J, Rickels K (1996) Reliability and validity of a daily diary for premenstrual syndrome. Psychiatry Res 65: 97-106

Gold J H (1994) Historical perspective of premenstrual syndrome. In Gold H S, Severino S K (eds), Premenstrual Dysphoria: Myths and Realities. American Psychiatry Association, New York, NY, pp. 171-183

Halbreich U (2003) The etiology, biology, and evolving pathology of premenstrual syndromes. Psychoneuroendocrinology 28 (Suppl. 3): 55-99

Halbreich U, Borenstein J, Pearlstein T, Kahn L S (2003) The prevalence, impairment, impact, and burden of premenstrual dysphoric disorder (PMS/PMDD). Psychoneuroendocrinology 28 (Suppl. 3): 1-23

Hamilton J A, Parry B L, Alagna S, Blumenthal S, Herz E (1984) Premenstrual mood changes: a guide to evaluation and treatment. Psychiatr Ann 14: 426-435

Harmer C J, Bhagwagar Z, Cowen P J, Goodwin G M (2002) Acute administration of citalopram facilitates memory consolidation in healthy volunteers. Psychopharmacology 163: 106-110

Harrison B J, Olver J S, Norman T R, Burrows G D, Wesnes K A, Nathan P J (2004) Selective effects of acute serotonin and catecholamine depletion on memory in healthy women. J Psychopharmacol 18: 321-340

Kahneman D (1973) Attention and Effort. Prentice Hall, Englewood Cliffs, NJ Keenan P A, Lindamer L A, Jong S K (1995) Menstrual phase-independent retrieval deficit in women with PMS. Biol Psychiatry 38: 369-377

Kimura D (2002) Sex hormones influence human cognitive pattern. Neuro Endocrinol Lett 23: 67-77

Kouri E M, Halbreich U (1997) State and trait serotonergic abnormalities in women with dysphoric premenstrual syndromes. Psychopharmacol Bull 33: 767-770

Man M S, MacMillan I, Scott J, Young A H (1999) Mood, neuropsychological function and cognitions in premenstrual dysphoric disorder. Psychol Med 29: 727-733 
Markus C R, Olivier B, De Haan E E H F (2002) Whey protein rich alphalactalbumin increases the ratio of plasma tryptophan to the sum of the other large neutral amino acids and improves cognitive performance in stress-vulnerable subjects. Am J Clin Nutr 75: 1051-1056

Markus C R, Olivier B, Panhuysen G E M, van der Gugten J, Alles M S, Tuiten A, Westenberg H G M, Fekkes D, Koppeschaar H F, De Haan E E H F (2000a) The bovine protein alpha-lactalbumin increases the plasma ratio of tryptophan to the other large neutral amino acids, and in vulnerable subjects raises brain serotonin activity, reduces cortisol concentration, and improves mood under stress. Am J Clin Nutr 71: $1536-1544$

Markus C R, Panhuysen G, Tuiten A, Koppeschaar H (2000b) Effects of food on cortisol and mood in vulnerable subjects under controllable and uncontrollable stress. Physiol Behav 70: 333-342

Melke J, Westberg L, Landen M, Sundblad C, Eriksson O, Baghei F, Rosmond R, Eriksson E, Ekman A (2003) Serotonin transporter gene polymorphisms and platelet $[3 \mathrm{H}]$ paroxetine binding in premenstrual dysphoria. Psychoneuroendocrinology 28: 446-458

Morgan M, Rapkin A (2002) Cognitive flexibility, reaction time, and attention in women with premenstrual dysphoric disorder. J Gend Specif Med 5: 28-36

Morgan M, Rapkin A J, D’Elia L, Reading A, Goldman L (1996) Cognitive functioning in premenstrual syndrome. Obstet Gynecol 88 : 961-966

Mortola J F, Girton L, Beck L, Yen S S (1990) Diagnosis of premenstrual syndrome by a simple, prospective, and reliable instrument: the calendar of premenstrual experiences. Obstet Gynecol 76: 302-307

Mumenthaler M S, O'Hara R, Taylor J L, Friedman L, Yesavage J A (2001) Relationship between variations in estradiol and progesterone levels across the menstrual cycle and human performance. Psychopharmacology 155: 198-203

Nakatani C, Sato N, Matsui M, Matsunami M, Kumashiro M (1993) Menstrual cycle effects on a VDT-based simulation task: cognitive indices and subjective ratings. Ergonomics 36: 331-339

Oken B S, Kishiyama S S, Salinsky M C (1995) Pharmacologically induced changes in arousal: effects on behavioral and electrophysiologic measures of alertness and attention. Electroencephalogr Clin Neurophysiol 95: 359-371

Owen A M, Sahakian B J, Hodges J R, Polkey C E, Summers B A, Robbins T W (1995) Dopamine-dependent fronto-striatal planning deficits in early Parkinson's Disease. Neuropsychology 9: 126-140

Owens J F, Matthews K A, Everson S A (2002) Cognitive function effects of suppressing ovarian hormones in young women. Menopause 9: $227-235$

Pearlstein T (2002) Selective serotonin reuptake inhibitors for premenstrual dysphoric disorder: the emerging gold standard? Drugs 62: 1869-1885

Phillips S M, Sherwin B B (1992a) Effects of estrogen on memory function in surgically menopausal women. Psychoneuroendocrinology 17: 485-495

Phillips S M, Sherwin B B (1992b) Variations in memory function and sex steroid hormones across the menstrual cycle. Psychoneuroendocrinology 17: 497-506

Pollack I, Norman D A (1964) A non-parametric analysis of recognition experiments. Psychon Sci 1: 125-126

Ramcharan S, Love E J, Fick G H, Goldfien A (1992) The epidemiology of premenstrual symptoms in a population-based sample of 2650 urban women: attributable risk and risk factors. J Clin Epidemiol 45: 377-392

Rapkin A (2003) A review of treatment of premenstrual syndrome and premenstrual dysphoric disorder. Psychoneuroendocrinology 28 (Suppl. 3): 39-53
Rapkin A J, Edelmuth E, Chang L C, Reading A E, McGuire M T, Su T P (1987) Whole-blood serotonin in premenstrual syndrome. Obstet Gynecol 70: 533-537

Reilly J G, McTavish S F B, Young A H (1997) Rapid depletion of plasma tryptophan: a review of studies and experimental methodology. J Psychopharmacol 11: 381-392

Resnick A (1998) Neuropsychological performance across the menstrual cycle in women with and without premenstrual dysphoric disorder. Psychiatry Res 77: 147-158

Rey A (1964) L'examen psychologique dans les cas d'encéphalopathie traumatique. Presses Universitaires de France, Presses Universitaires de France, Paris

Riedel W J, Klaassen T, Deutz N E P, Van Someren A, Van Praag H M (1999) Tryptophan depletion in normal volunteers produces selective impairment in memory consolidation. Psychopharmacology 141: 362-369

Riedel W J, Klaassen T, Schmitt J A J (2002) Tryptophan, mood and cognitive function. Brain Behav Immun 16: 581-589

Rojansky N, Halbreich U, Zander K, Barkai A, Goldstein S (1991) Imipramine receptor binding and serotonin reuptake in platelets of women with premenstrual changes. Gynecol Obstet Invest 31: $146-152$

Rosenthal N E, Genhart M J, Caballero B, Jacobsen F M, Skwerer R G, Coursey R D, Rogers S, Spring B J (1989) Psychobiological effects of carbohydrate- and protein-rich meals in patients with seasonal affective disorder and normal controls. Biol Psychiatry 25: 1029-1040

Rubinsztein J, Rogers R D, Riedel W J, Mehta M A, Robbins T W, Sahakian B J (2001) Acute dietary tryptophan depletion impairs affective shifting and delayed visual recognition in healthy volunteers. Psychopharmacology 154: 319-326

Sayegh R, Schiff I, Wurtman J, Spiers P, McDermott J, Wurtman R (1995) The effect of a carbohydrate-rich beverage on mood, appetite, and cognitive function in women with premenstrual syndrome. Obstet-Gynecol 86: $520-528$

Schmidt P J, Nieman L K, Danaceau M A, Adams L F, Rubinow D R (1998) Differential behavioral effects of gonadal steroids in women with and in those without premenstrual syndrome. N Engl J Med 338: 209-216

Schmitt J A, Jorissen B L, Sobczak S, van Boxtel M P, Hogervorst E, Deutz N E, Riedel W J (2000) Tryptophan depletion impairs memory consolidation but improves focussed attention in healthy young volunteers. J Psychopharmacol 14: 21-29

Shallice T (1982) Specific impairments of planning. Phil Trans of the Royal Society of London 298: 199-209

Sobczak S, Riedel W J, Booij L, Aan het Rot M, Deutz N E P, Honig A (2002) Cognition following Acute Tryptophan Depletion: differences between first-degree relatives of bipolar disorder patients and matched healthy control volunteers. Psychol Med 32: 503-515

Steege J F, Stout A L, Knight D L, Nemeroff C B (1992) Reduced platelet tritium-labeled imipramine binding sites in women with premenstrual syndrome. Am J Obstet Gynecol 167: 168-172

Steinberg S, Annable L, Young S N, Liyanage N (1999) A placebo-controlled clinical trial of L-tryptophan in premenstrual dysphoria. Biol Psychiatry 45: 313-320

Taylor D L, Mathew R J, Ho B T, Weinman M L (1984) Serotonin levels and platelet uptake during premenstrual tension. Neuropsychobiology 12: $16-18$

Teff K L, Young S N, Blundell J E (1989) The effect of protein or carbohydrate breakfasts on subsequent plasma amino acid levels, satiety and nutrient selection in normal males. Pharmacol Biochem Behav 34: $829-837$ 
Ussher J M, Wilding J M (1991) Performance and state changes during the menstrual cycle, conceptualised within a broad band testing framework. Soc Sci Med 32: 525-534

van Eijk H M, Rooyakkers D R, Deutz N E (1993) Rapid routine determination of amino acids in plasma by high-performance liquid chro- matography with a 2-3 microns Spherisorb ODS II column. J Chromatogr 620: 143-148

Young S N (1996) Behavioral effects of dietary neurotransmitter precursors: basic and clinical aspects. Neurosci Biobehav Rev 20: 313-323 